Check for updates

1 London

Cite this as: BMJ 2022;376:040 http://dx.doi.org/10.1136/bmj.040 Published: 07 January 2022

\section{The cold water cut through my numbness}

\section{Cold water swimmers are keen to extol the health benefits, but is there any evidence asks Julian Sheather, and what are the risks?}

\section{Julian Sheather medical ethicist}

It is six o'clock in the morning and I am in bed. It is warm, but in just over an hour, long before the sun breaks through the encircling trees, I will be swimming in water so cold it will make my bones ache and my skin burn. Why do I do this?

Cold water swimming is certainly in fashion. According to the New Scientist, an estimated 7.5 million people now swim outdoors in the UK, with more and more braving the winter months. ${ }^{1}$ Long derelict lidos are reopening. Neglected tide pools, sea-refreshed twice a day, are having the sand and shingle dug out. Despite water companies trying to turn them into sewers, people are again swimming in our rivers and lakes-brave souls in swimming hats, trailing fluorescent tow floats, going eye to eye with the coots. No, it is not glamorous. It is not about the body beautiful. As soon as we can, we wrap our frozen bodies in shapeless robes and bury our heads in woolly hats, clutching hot drinks in gloved hands. So why do we do it?

Ask a bunch of swimmers and at some point someone will mention the health benefits. We know that swimming is good for us-among the kindest of exercises. But when the water is seriously cold, there is not so much swimming done. As the water sinks towards zero it is more of a plunge. Ask a cold water swimmer though and they will talk of boosted immune systems, of re-charged libidos and endorphin rushes, of stress-relief and balm for anxiety and depression, of unexpected comfort in times of loss.

I started because I had a hit of depression. The cold water cut through my numbness. It helped cool the cauldron my body had become. No, it isn't a cure-depression can return-but it is the most wonderful palliative, the first thing I lean on when the Furies are about. But beyond the ironclad convictions of diehards like me, what are the data? Is it actually good for you?

My experience was echoed in a 2018 case study in BMJ Case Reports. ${ }^{2}$ A 24-year-old woman laid low for seven years with drug resistant (fluoxetine and citalopram) anxiety and depression started cold water swimming, enjoying an "immediate" lift in mood then a "gradual reduction" in depression's baleful symptoms. A case study, beguiling though it is, is only a case study. Hand on heart I couldn't say what part of my relief is cold water, what part the low-key camaraderie, what part being outdoors and flushed with whatever light a winter dawn delivers. But the tide of anecdotal evidence is prompting serious research. Hormesis may have a hand in it: that harmful things can be beneficial in small doses. ${ }^{3}$ Controlled exposure to the stress of cold-water immersion might help inoculate against other stressors. Research also suggests that cold water can help reduce inflammation-also linked to depression-and may help with some auto-immune disorders. ${ }^{4}$ There is also increasing interest in the possible effects of cold water on dementia, with evidence suggesting that the "cold-shock" protein $\mathrm{RBM}_{3}$, released in the brain in response to body cooling, guards against neurodegeneration. ${ }^{5}$

Although too early to say if it will be a panacea for absolutely all our ills, there is of course a downside to cold water swimming - the cold water. According to Mike Tipton, professor at Portsmouth University, getting into water less than $15^{\circ} \mathrm{C}$ triggers cold water shock-including an involuntary gasp reflex difficult to suppress and downright dangerous if your mouth is under water-and among the most common causes of drowning. When the temperature drops below eight degrees it triggers your skin's pain receptors. And hurts. Then there is the risk of hypothermia. I have had it once and for reasons unknown to me I had no idea I was succumbing until I got out of the pool and tried to walk. It scared the daylights out of me-and I needed a hot bath to recover. So, if you do fancy giving it a go heed the advice on the Outdoor Swimming website, and follow these few tips to stay safe and enjoy yourself ${ }^{6}$ :

Acclimatise: start when the water is warmer and follow the temperature down

Don't overdo it: start small. Hypothermia can come on insidiously, so find your limits and stay inside them. If you start to feel unexpectedly warm or euphoric, get out straight away

Dress right: wear a swim cap or two when you're in the water, and loads of layers for warming up after. When it gets really sharp, neoprene gloves and boots can ease the pain.

Swim social: Don't swim in open water on your own-take a friend

Swim where it is safe: open water can be dangerous. I started out in the safety of Tooting Lido, overseen by lifeguards. Only swim where you know the risks and make sure you know where you will get out before you get in

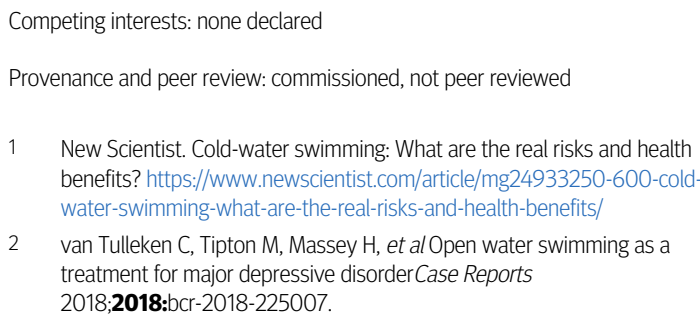

New Scientist. Cold-water swimming: What are the real risks and health benefits? https://www.newscientist.com/article/mg24933250-600-coldwater-swimming-what-are-the-real-risks-and-health-benefits/

2 van Tulleken C, Tipton M, Massey H, et al Open water swimming as a treatment for major depressive disorderCase Reports 2018;2018:bcr-2018-225007. 


\section{OPINION}

3 Hormesis. https://www.sciencedirect.com/topics/agricultural-and-biological-sciences/hormesis

4 Buijze GA, De Jong HMY, Kox M, etal. An add-on training program involving breathing exercises, cold exposure, and meditation attenuates inflammation and disease activity in axial spondyloarthritis - A proof of concept trial. PLOS One 2019;14:e225749.

doi: 10.1371/journal. pone.0225749. pmid: 31790484

5 Peretti D, Bastide A, Radford H, etal. RBM3 mediates structural plasticity and protective effects of cooling in neurodegeneration. Nature 2015:518:236-9.

doi: 10.1038/nature14142. pmid: 25607368

6 The Outdoor Swimming Society. https://www.outdoorswimmingsociety.com/category/survive/getting-started/ 